\title{
The prevalence of breast variations among women of reproductive age in an Iranian community
}

\author{
Vazirinejad R, $\mathrm{PhD}^{1}$, Manshoori N, $\mathrm{PhD}^{2}$, Mohamadpanah N, $\mathrm{MD}^{3}$, Gomnami N, $\mathrm{PhD}^{4 *}$ \\ 1- Professor, PhD in Epidemiology, Social Determinants of Health Research Centre, Medical School, Rafsanjan \\ University of Medical Sciences, Rafsanjan, Iran. 2- Assistant Prof., in Pediatrics, Medical School, Ali-ebn \\ Abitaleb Hospital, Rafsanjan University of Medical Sciences, Rafsanjan, Iran. 3- Medical Student, Dept. of Social \\ Medicine, Medical School, Rafsanjan University of Medical Sciences, Rafsanjan, Iran. 4- Assistant Prof., Azad \\ University of Mashhad, Mashhad, Iran.
}

\begin{abstract}
Received: August 2015, Accepted: September 2015

Background: Breast variations play an important role in breastfeeding success. It seems that this issue has not gained enough attention. The present study was designed to measure the prevalence of breast variations among women of reproductive age in an Iranian community.

Materials and Methods: In this cross-sectional study, a sample of 402 pregnant women who were referred to the only maternal hospital of Rafsanjan county, Iran, was randomly recruited for the study. There were 20 items on the checklist in two sections including 14 demographic and 6 specific items. Trained physicians recorded the data in the checklist through interviewing the mothers and using their physical examination after receiving respondents' consent. Data were analyzed using SPSS software. In addition to descriptive methods, the level of risk of breastfeeding failure with $95 \%$ CI was calculated. Normally distributed continuous variables were compared using the independent t-test and the Mann-Whitney $\mathrm{U}$ test was used to compare discrete variables and those continuous variables that were not normally distributed.

Results: Of 402 mothers who accepted to participate, 51 mothers were detected with at least one type of breast variation giving a prevalence of 127 per 1000 mothers. The most common type of breast variation was "flat nipple" $(\mathrm{n}=34)$. The existence of at least one type of breast variation among mothers increased the risk of failure in the breastfeeding process 14.1 times. Having "flat nipple" increased the risk of breastfeeding failure 11.6 times.

Conclusions: In addition to the high prevalence of breast variation among the study population, our findings illustrated its significant negative effect on breastfeeding success. Thus, health professionals' skills must be developed in the management of breastfeeding among mothers with this problem and mothers need to be given appropriate advice on how to counteract resulted breastfeeding difficulties. More investigations are strongly recommended.
\end{abstract}

Keywords: Breast, Breastfeeding, Nipples, Reproductive.

\section{Introduction}

The outstanding privilege of exclusive breastfeeding in newborn babies regarding the vital role of breastfeeding from different perspectives is very well-known (1-5). Due to the importance of breastfeeding in communities' health improvement, mothers have been encouraged to feed their babies with their own milk. Furthermore, factors related to this problem have been studied.

Mothers' intentions* to breastfeed babies are recognized as the most important factor that influences breastfeeding (6-8). However, there are some other factors

\footnotetext{
* Corresponding author: Naser Gomnami, Azad University of Mashhad, Mashhad, Iran.

Email: gommnami_nasser@yahoo.com
} 
which are not highlighted enough and could be critically important. For instance, anatomical breast variations, in particular among first-time mothers, who are less experienced, result in unsuccessful breastfeeding (9). Breastfeeding success depends on correct sucking in which the nipple and much of the areola are drawn well into the baby's mouth (6). Breast variations act as barriers for babies to a suitable situation when breastfeeding. Moreover, a mother's intention to start and/or to continue breastfeeding could be affected by many factors of which bad experience with past breastfeeding $(8,10)$ could be due to a type of breast variation. An association between "deciding to breastfeed prior to becoming pregnant compared with making a later decision" and "longer duration of breastfeeding" has been reported by Forster et al. (7).

The effect of anatomical variations of the mother's breast on neonate's weight gain in the first 7 days of life has been shown in a research conducted by this Vazirinejad et al (9). On the other hand, many studies have been conducted to explore factors associated with breastfeeding in both developed and developing communities (10-14).

Some types of breast variations have been recorded as problems in establishing and maintaining breastfeeding. For instance, in the study by Alexander et al., inverted and non-protractile nipples were considered to be a cause of breastfeeding problems and two different methods were compared for resolving these problems among pregnant women (15). They assumed that inverted nipple would be detected if "it was situated on a plane below the areola" (1517). Maternal obesity and its effect on breastfeeding behavior and/or infants' weight gain have also been investigated by Forster et al. (7) and Mok et al. (11). The association between mothers' obesity and both breastfeeding and infants' weight gain was confirmed in these studies.
All these results show that breast variations play an important role in maternal breastfeeding behavior and it seems that this problem has not attracted attention proportionally by health service providers. The effect of this problem could be controlled in different ways. The training of mothers on how to recognize and overcome this problem, in particular among first-time mothers, could be very helpful in improving the breastfeeding process. However, as the first step to planning for such a program, we must measure the load of this problem among mothers living in different communities.

Therefore, the present study was designed to measure the prevalence of breast variations among women of reproductive age in an Iranian community.

\section{Materials and Methods}

This was a cross-sectional study. A sample of 402 pregnant women who were referred to the only maternal hospital of Rafsanjan (Niknafs Hospital), Iran, a public-sector referral hospital, affiliated to the University of Rafsanjan, during a 6-month period was recruited for the study. This group of women of reproductive age was randomly selected from the list of all pregnant women who referred to the center during 6 months, from $1^{\text {st }}$ January to $30^{\text {th }}$ June 2007. About 3500 to 4000 pregnant women were referred to this hospital to give birth during this period.

The study checklist was used for recording data. There were 20 items on the checklist in two sections including 14 demographic and 6 specific items. Trained physicians were requested to answer the items on the checklist by interviewing the mothers and performing physical examinations.

Trained female general practitioners were requested to distinguish breast variations through breast physical examination.

Variations of large nipple, flat nipple, inverted nipple, uneven nipples, and 
abnormally huge breast were detected on physical examinations. In this study, based on the practical definition, a nipple was abnormally large, abnormally flat, inverted or abnormally uneven, and abnormally large, if it was impossible for the mother to breastfeed her baby normally, and without receiving any help from others and/or equipment. The specialist was requested to confirm the problem resulting from these variations by watching the breastfeeding process for all respondents after giving birth. Since mothers were assigned to the two groups of mothers with and without breast variation before giving birth, it was probable for the specialist (the observer) to make a mistake in this stage. Therefore, the mother and her baby were excluded or allocated to the other group if the specialist realized that her diagnosis was not correct after watching the breastfeeding process.

The study sample size was calculated by conducting a pilot study on 25 mothers giving a proportion of $8 \%$ for mothers with at least 1 type of breast variation. With a confidence interval of $95 \%, \mathrm{P}=$ 0.08 , and $d=0.02$, a sample size of 378 was calculated. We decided to invite 420 mothers considering a drop out of $15 \%$.

Of the 420 mothers who were invited, 402 signed a written consent form after receiving the details of study methods and objectives. Each day, between 20 and 30 mothers refer to the center for giving births. Therefore, for the duration of 6 months, 4 to 5 mothers were randomly invited to be surveyed each day.

Information about some demographic variables, the existence of breast variation, and the type of breast variations were recorded in the checklist. Demographic variables included mother's age, educational status, occupation, and place of residence (urban/rural).

Data were analyzed using SPSS software (version 14, SPSS Inc., Chicago, IL, USA). Continuous variables were summarized using mean and 95\% confidence intervals, while categorical variables were summarized as ratios and percentages.

Cross-tabulations of categorical variables with the existence of breast variation were produced and statistical associations between these categorical variables were studied using chi-square test. Normally distributed continuous variables were compared using independent t-test. MannWhitney $U$ test was used to compare discrete variables and those continuous variables that were not normally distributed.

\section{Results}

For the duration of this study, about 4000 mothers were admitted to Niknafs Hospital to give birth, of which 420 mothers were randomly selected and invited to participate in the study, and 402 accepted to participate. Overall, 51 mothers were detected with at least 1 type of breast variation giving a prevalence of 127 per 1000 mothers.

Mean age of respondents in the two groups of mothers with and without breast variation were $25.8 \pm 4.8$ and $27.3 \pm 5.8$ years. The difference between these two mean ages was not significant.

The frequency distribution of mothers based on some demographic variables is presented in table 1. No statistical difference in the proportion of mothers with breast variation exists between the different groups of mothers based on their educational status, occupation, social class, and place of residence.

Through dividing the gestation age of pregnant mothers in the two groups of less than 38 weeks and more or equal to 38 weeks, a statistical difference in proportion of mothers with breast variation was observed between the two groups. The proportion of mothers with breast variation was significantly higher among mothers 
with gestation age of less than 38 weeks in comparison with mothers with gestation age of more or equal to 38 weeks. As table 1 shows, about $18 \%$ of mothers who had at least 1 type of breast variation, also had a gestation age of less than 38 weeks. Whereas, gestation age of only $8.5 \%$ of mothers without breast variation was less than 38 weeks (Table 1).

Table 1: The frequency of study respondents based on some demographic variables

\begin{tabular}{|c|c|c|c|c|c|c|}
\hline \multirow{3}{*}{ Demographic variables } & \multicolumn{4}{|c|}{ Breast variation } & \multirow{2}{*}{\multicolumn{2}{|c|}{ Total }} \\
\hline & \multicolumn{2}{|c|}{ Yes } & \multicolumn{2}{|c|}{ No } & & \\
\hline & No. & $\%$ & No. & $\%$ & No. & $\%$ \\
\hline $\begin{array}{l}\text { Educational status } \\
\text { - Illiteracy } \\
\text { - Primary/secondary } \\
\text { - High school/diploma } \\
\text { - Higher }\end{array}$ & $\begin{array}{c}0 \\
19 \\
23 \\
9\end{array}$ & $\begin{array}{c}0.0 \\
37.3 \\
45.0 \\
17.7\end{array}$ & $\begin{array}{c}4 \\
170 \\
135 \\
42\end{array}$ & $\begin{array}{c}1.1 \\
48.5 \\
38.4 \\
12.0\end{array}$ & $\begin{array}{c}4 \\
189 \\
159 \\
50\end{array}$ & $\begin{array}{c}1.0 \\
47.0 \\
39.6 \\
12.4\end{array}$ \\
\hline $\begin{array}{l}\text { Occupation } \\
\text { - Labor } \\
\text { - Employee } \\
\text { - Housekeeper }\end{array}$ & $\begin{array}{c}2 \\
2 \\
47\end{array}$ & $\begin{array}{c}3.9 \\
3.9 \\
92.2\end{array}$ & $\begin{array}{c}10 \\
36 \\
305\end{array}$ & $\begin{array}{c}2.8 \\
10.3 \\
86.9\end{array}$ & $\begin{array}{c}12 \\
38 \\
352\end{array}$ & $\begin{array}{c}3.0 \\
9.5 \\
87.6\end{array}$ \\
\hline $\begin{array}{l}\text { Social class } \\
\text { - Low } \\
\text { - Moderate } \\
\text { - High }\end{array}$ & $\begin{array}{c}41 \\
8 \\
2\end{array}$ & $\begin{array}{c}80.4 \\
15.7 \\
3.9\end{array}$ & $\begin{array}{c}292 \\
58 \\
1\end{array}$ & $\begin{array}{c}83.2 \\
16.5 \\
0.3\end{array}$ & $\begin{array}{c}333 \\
66 \\
3\end{array}$ & $\begin{array}{c}82.8 \\
16.4 \\
0.7\end{array}$ \\
\hline $\begin{array}{l}\text { Place of residence } \\
\text { - City } \\
\text { - Village }\end{array}$ & $\begin{array}{l}26 \\
25\end{array}$ & $\begin{array}{l}51.0 \\
49.0\end{array}$ & $\begin{array}{l}186 \\
165\end{array}$ & $\begin{array}{l}53.0 \\
47.0\end{array}$ & $\begin{array}{l}212 \\
190\end{array}$ & $\begin{array}{l}52.7 \\
47.3\end{array}$ \\
\hline $\begin{array}{l}\text { Gestation age* } \\
<38 \text { weeks } \\
\geq 38 \text { weeks }\end{array}$ & $\begin{array}{c}9 \\
42\end{array}$ & $\begin{array}{l}17.6 \\
82.4\end{array}$ & $\begin{array}{c}30 \\
321\end{array}$ & $\begin{array}{c}8.5 \\
91.5\end{array}$ & $\begin{array}{c}39 \\
363\end{array}$ & $\begin{array}{c}9.7 \\
90.3\end{array}$ \\
\hline
\end{tabular}

*- significant difference between the two groups of mothers with and without breast variation (P $<0.05)$

The results showed that the most common type of breast variation in respondents was flat nipple $(\mathrm{n}=34)$ and the second most common type was inverted nipple $(\mathrm{n}=10)$ (Table 2). No case of huge breast was detected among respondents and the frequency of uneven nipple and big nipple was almost the same in the respondents ( $\mathrm{n}$ $=4$ and $\mathrm{n}=5$, respectively). The results presented in table 2 show that the majority $(72.7 \%)$ of respondents who reported at least 1 type of breast variation also had problems with breastfeeding their neonates.

Table 2: The frequency of mothers with different types of breast variation based on their problem with breastfeeding

\begin{tabular}{ccccccc}
\hline \multirow{2}{*}{$\begin{array}{c}\text { Breast } \\
\text { variation* }\end{array}$} & \multicolumn{3}{c}{ Breastfeeding problem } & \multicolumn{2}{c}{ Total } \\
\cline { 2 - 7 } & No. & $\%$ & No. & $\%$ & No. & $\%$ \\
\hline Big nipple & 5 & 100 & 0 & 0 & 5 & 100 \\
\hline Inverted nipple & 7 & 70 & 3 & 30 & 10 & 100 \\
\hline Uneven nipple & 2 & 50 & 2 & 5 & 4 & 100 \\
\hline Flat nipple & 24 & 70.6 & 10 & 29.4 & 34 & 100 \\
\hline total & 40 & 72.7 & 15 & 27.3 & 55 & 100
\end{tabular}

*- There were no respondents with huge breast.

**. Four respondents had 2 types of breast variations. 
The risk levels of breastfeeding failure among mothers with different types of breast variation are presented in table 3 . As the table shows, the existence of at least 1 type of breast variation, including big nipple, inverted nipple, uneven nipple, and flat nipple, among mothers would increase the risk of problems in the breastfeeding process 14.1 times. This level of risk is also calculated for each type of breast variation. For instance, the existence of flat nipple among mothers would increase the risk of breastfeeding failure 11.6 times.

Table 3: The risk levels of breastfeeding failure (with 95\% confidence interval) among mothers with different types of breast variation in the present study

\begin{tabular}{|c|c|c|c|c|c|c|}
\hline \multirow{3}{*}{ Breast variation* } & \multicolumn{4}{|c|}{ Breastfeeding problem } & \multirow{3}{*}{$\mathrm{P}$} & \multirow{3}{*}{ Risk $(95 \% \mathrm{CI})$} \\
\hline & \multicolumn{2}{|c|}{ Yes } & \multicolumn{2}{|c|}{ No } & & \\
\hline & No. & $\%$ & No. & $\%$ & & \\
\hline $\begin{aligned} \text { Big nipple } & \\
- & \text { Yes } \\
- & \text { No }\end{aligned}$ & $\begin{array}{c}5 \\
82\end{array}$ & $\begin{array}{l}100 \\
20.7\end{array}$ & $\begin{array}{c}0 \\
314\end{array}$ & $\begin{array}{l}0 \\
79.3\end{array}$ & $<0.001$ & $4.8(4.0-5.8)$ \\
\hline $\begin{array}{r}\text { Inverted nipple } \\
-\quad \text { Yes } \\
-\quad \text { No }\end{array}$ & $\begin{array}{c}7 \\
80\end{array}$ & $\begin{array}{l}70.0 \\
20.5\end{array}$ & $\begin{array}{c}3 \\
311\end{array}$ & $\begin{array}{l}30.0 \\
79.5\end{array}$ & $<0.001$ & $9.1(2.3-35.9)$ \\
\hline $\begin{array}{r}\text { Uneven nipple } \\
-\quad \text { Yes } \\
-\quad \text { No }\end{array}$ & $\begin{array}{c}2 \\
85\end{array}$ & $\begin{array}{l}50.5 \\
21.4\end{array}$ & $\begin{array}{c}2 \\
312\end{array}$ & $\begin{array}{l}50.0 \\
78.6\end{array}$ & 0.167 & $3.7(0.5-26.4)$ \\
\hline $\begin{aligned} \text { Flat nipple } & \\
- & \text { Yes } \\
- & \text { No }\end{aligned}$ & $\begin{array}{l}24 \\
63\end{array}$ & $\begin{array}{l}70.6 \\
17.2\end{array}$ & $\begin{array}{c}10 \\
304\end{array}$ & $\begin{array}{l}29.4 \\
82.8\end{array}$ & $<0.001$ & $11.6(5.3-25.4)$ \\
\hline $\begin{array}{c}\text { At least one type } \\
-\quad \text { Yes } \\
-\quad \text { No }\end{array}$ & $\begin{array}{l}36 \\
51\end{array}$ & $\begin{array}{l}70.6 \\
14.6\end{array}$ & $\begin{array}{c}15 \\
299\end{array}$ & $\begin{array}{l}29.4 \\
85.4\end{array}$ & $<0.001$ & $14.1(7.2-27.5)$ \\
\hline
\end{tabular}

\section{Discussion}

The prevalence of 127 per 1000 mothers with at least 1 type of breast variation obtained in our study is considerably high. On the other hand, our results also showed that the existence of at least 1 type of breast variation would significantly increase the risk level of breastfeeding failure among mothers. Increasing this level of risk as much as 14 times shows that interventions for reducing or controlling the negative effects of the problem are necessary. Furthermore, a pervious study illustrated that breast variations among mothers has an inverse relationship with the weight of neonates in the first few days of life (9). A factor that could worsen the problem is that mothers with breast variation might get exhausted and decide to stop breastfeeding their baby and use formula milk to feed them. Many studies have concluded that mothers' intention is one of the most important factors affecting their behavior for feeding neonates $(10,18)$. However, the role of breast variation in this issue could be critically important. Our findings also showed that about $73 \%$ of breast variations resulted in breastfeeding failure. This means at least three-fourths of breast variations among mothers in the population of this study require interventions. Since 127 of 1000 mothers in the study community suffer from at least 1 type of breast variation and about $75 \%$ of these variations cause breastfeeding failure, about 95 of 1000 
mothers require appropriate interventions. This proportion is considerably high, and thus, every piece of work which controls the effect of breast variation on breastfeeding would have massive advantages. Considering the benefits for babies' (19-20) and mothers' (21-22) health which is confirmed by pervious investigations, and socio-economical benefits of breastfeeding which are also well documented (23), it seems that detection and control programs for this breastfeeding barrier among mothers would be cost-effective. Moreover, this would be more important with regard to our results that show the majority of mothers with breast variations classified as lowincome social class.

A previous study has also reported that about $10 \%$ of pregnant women who intend to breastfeed have inverted or nonprotractile nipples (Southampton, UK, in 1987-9) (10).

Our findings showed that about $81 \%$ of breast variations were detected among mothers of low social class. This majority of mothers with breast variation are living in poverty. In this group of mothers, it is not easy to prepare a nutrient replacement for breastfeeding. In other words, poverty would worsen the disadvantage of having a breast variation. Therefore, this makes the problem more critical and more attention should be paid to the problem of breast variations among mothers living in the study community.

The findings of this study illustrated the significant negative effect of the existence of breast variation on breastfeeding behavior among mothers, and that interventions are needed to decrease this disadvantage. In the first step, breast variations should be detected and, in particular, first-time mothers must be made aware of their breast variation. Therefore, breast examinations should be performed for all mothers and, in case of existence of breast variation, suitable advice should be presented. Most often, first-time mothers are not aware of their breast variation and think they are unable to breastfeed their neonates and might give up and seek alternative methods to feed their babies. Suitable consultation by experts would help mothers with breast variations to overcome this barrier for breastfeeding. Detection of breast variation type would help the selection of an adequate resolution for the problem. This might be only a suitable position for the mother and her baby or might be equipment that help mothers feed their babies.

Flat nipple was the most common type of breast variation among mothers in our study followed by inverted nipple. An effective breastfeeding baby usually has little trouble breastfeeding even if the mother's nipples appear to be flat. Although the benefit of using hard plastic breast shells is not conclusive, some mothers find it helps to wear them in their bra between feedings. Breast shells exert a small amount of traction to help draw the nipple outward. However, Alexander et al. concluded that "recommending nipple preparation with breast shells may reduce the chances of successful breast feeding" (15). Using a breast pump to draw the nipple out just prior to breastfeeding may also help.

In two studies, attempts have been made to increase the prevalence of breastfeeding among mothers through peer counseling method as a community-based intervention in Glasgow, UK (19), and Hong Kong (20). Results showed that this method was not successful in sustaining breastfeeding practice. For educating mothers with breast variation, experts could help through performing breast physical examination and providing appropriate advice along with teaching them how to breastfeed babies. All this could be done during the last few months of pregnancy just before giving birth as a part of the routine mother care program. 


\section{Conclusions}

The findings of this study confirm the results of the previous studies in this community in that the effect of mothers' breast variations can be considered important enough for providing routine breast examination for pregnant women. For this purpose, health professionals' skills must be developed in the management of breastfeeding among mothers with this problem. Mothers need to be aware of these variations and also be given appropriate advice on how to counteract breastfeeding difficulties. However, additional investigations are strongly recommended.

\section{Acknowledgments}

The authors would like to thank the participants for making this study possible and Niknafs Hospital staff for their help. The authors would also like to thank the Social Determinants of Health Research Center for their financial support.

\section{Conflict of interest: None declared}

\section{References}

1. Ladomenou F, Moschandreas J, Kafatos A, Tselentis Y, Galanakis E. Protective effect of exclusive breastfeeding against infections during infancy: a prospective study. Arch Dis Child 2010; 95(12):10048.

2. Paricio Talayero JM, Lizán-García M, Otero Puime A, Benlloch Muncharaz MJ, Beseler Soto B, Sánchez-Palomares M, et al. Full breastfeeding and hospitalization as a result of infections in the first year of life. Pediatrics 2006; 118(1):e92-9.

3. Kusunoki T, Morimoto T, Nishikomori R, Yasumi T, Heike T, Mukaida $\mathrm{K}$, et al. Breastfeeding and the prevalence of allergic diseases in schoolchildren: Does reverse causation matter? Pediatr Allergy Immunol 2010; 21(1 Pt 1):60-6.

4. Mortensen EL, Michaelsen KF, Sanders SA, Reinisch JM. The association between duration of breastfeeding and adult intelligence. JAMA 2002; 287(18):236571.
5. Li SC, Kuo SC, Hsu YY, Lin SJ, Chen PC, Yi CC. Effect of Breastfeeding Duration on Infant Growth Until 18 Months of Age: A National Birth Cohort Study. J Exp Clin Med 2010; 2(4):165-72.

6. American Academy of pediatrics. Breastfeeding handbook for physicians. United States of America: American Academy of pediatrics and American college of obstetricians and gynecologists; 2006. P.52-3.

7. Forster DA, McLachlan HL, Lumley J. Factors associated with breastfeeding at six months postpartum in a group of Australian women. Int Breastfeed J 2006; $1: 18$.

8. Kramer MS, Kakuma R. The optimal duration of exclusive breastfeeding: a systematic review. Adv Exp Med Biol 2004; 554:63-77.

9. Vazirinejad R, Darakhshan S, Esmaili A, Hadadian S. The effect of maternal breast variations on neonatal weight gain in the first sevan days of life. Int Breastfeed J 2009; 4:13.

10. McLnnes RJ, Love JG, Stone DH. Independent predictors of breastfeeding intention in a disadvantaged population of pregnant women. BMC Public Health 2001; 1:10.

11. Mok E, Multon C, Piguel L, Barroso E, Goua V, Christin P, et al. Decreased Full Breastfeeding, Altered Practices, Perceptions, and Infant Weight Change of Prepregnant Obese Women: A Need for Extra Support. Pediatrics 2008; 121(5):e1319-24.

12. Graham KI, Scott JA, Binns CW, Oddy WH. National targets for breastfeeding at hospital discharge have been achieved in Perth. Acta Paediatr 2005; 94(3):352-6.

13. Win NN, Binns CW, Zhao Y, Scott JA, Oddy WH. Breastfeeding duration in mothers who express breast milk: a cohort study. Int Breastfeed J 2006; 1:28.

14. Scott JA, Binns CW, Oddy WH, Graham KI. Predictors of breastfeeding duration: evidence from a cohort study. Pediatrics 2006; 117(4):e646-55.

15. Alexander JM, Grant AM, Campbell MJ. Randomised controlled trial of breast shells and Hoffman's exercises for inverted and non-protractile nipples. BMJ 1992; 304(6833):1030-2.

16. Plichta SB, Kelvin EA, Munro BH. Munro's Statistical Methods for Health Care Research. 6th ed. Philadelphia, USA: Wolters Kluwer Health/Lippincott Williams \& Wilkins; 2012.

17. Davies-Adetugbo AA, Ojofeitimi EO. Maternal education, breastfeeding behviours and lactational amenorrhoea: studies among two ethnic communities in Ile Ife, Nigeria. Nutr Health 1996; 11(2):115-26.

18. Amir LH, Donath S. A systematic review of maternal obesity and breastfeeding 
intention, initiation and duration. BMC Pregnancy and Childbirth 2007; 7:9.

19. Gartner LM, Morton J, Lawrence RA, Naylor AJ, O'Hare D, Schanler RJ, et al. Breastfeeding and the use of human milk. Pediatrics 2005; 115(2):496-506.

20. Hamosh M. Bioactive factors in human milk. Pediatr Clin North Am 2001; 48(1):69-86.

21. Collaborative Group on Hormonal Factors in Breast Cancer. Breast cancer and breastfeeding: collaborative reanalysis of ind ividual data from 47 epidemiological studies in 30 countries, including 50302 women with breast cancer and 96973 women without the disease. Lancet 2002; 360(9328):187-95.

22. Stuebe AM, Rich-Edwards JW, Willett
WC, Manson JE, Michels KB. Duration of lactation and incidence of type 2 diabetes. JAMA 2005; 294(20):2601-10.

23. Cattaneo A, Ronfani L, Burmaz T, Quintero-Romero S, Macaluso A, Di Mario S. Infant feeding and cost of health care: a cohort study. Acta Paediatr 2006; 95(5):540-6.

24. McInnes RJ, Love JG, Stone DH. Evaluation of a community-based intervention to increase breastfeeding prevalence. J Public Health Med 2000; 22(2):138-45.

25. Wong EH, Nelson E, Choi KC, Wong KP, Ip C, Ho LC. Evaluation of a peer counseling program to sustain breastfeeding practice in Hong Kong. Int Breastfeed J 2007; 2:12. 